\title{
EDUCACIÓN
}

\section{Influencia de la gestión del supervisor en el mejoramiento de las instituciones de educación escolar básica, de cuatro zonas del Departamento Central. Periodo 2008-2010}

\author{
Elvira Virginia Samaniego ${ }^{1}$
}

\begin{abstract}
Resumen
Introducción: Las últimas reformas educativas en América Latina no han tenido el resultado esperado a pesar de haber sido tratadas desde aspectos diferenciados y en varios momentos de la historia de las últimas décadas del siglo XX. Lo que pasa realmente en las aulas no ha cambiado mucho desde décadas atrás y este estancamiento tiene que ver con mecanismos de control y motivación en los procesos modernos de supervisión a los centros. Un estamento educativo como la supervisión de escuelas y colegios, es una herramienta esencial para llegar al docente y estrechar lo más posible, la distancia entre política educativa y la ejecución del currículum en el aula. Exige constancia, perseverancia, dedicación, competencia y entusiasmo para lograr sus metas. Pero no es suficiente un planificado sistema de control, las prácticas educativas rara vez tienen éxito sin un buen liderazgo, tanto a nivel de sistemas como a nivel de cada institución educativa. El liderazgo debe ser sostenido, comprometido y talentoso. ¿Cómo sortear las innumerables dificultades que se presentan a diario en las supervisiones educativas? Muchas veces se acude al supervisor como a una persona de confianza a quien se le presenta un problema con la intención de recibir una respuesta acertada. El supervisor debe estar preparado con múltiples herramientas de gestión, para el asesoramiento, motivación y control. La problemática que se presenta tiene dos aristas: por un lado, el estilo de gestión del supervisor y por otro lado, si ese estilo tiene influencia sobre los cambios para mejora de las instituciones educativas de la zona.
\end{abstract}

Objetivo: Determinar si los supervisores pedagógicos de cuatro zonas de Educación Escolar Básica del Departamento Central, con indicadores de buena gestión, según las evaluaciones realizadas por las autoridades pertinentes, influyen en el mejoramiento de las instituciones de su sector en el periodo comprendido entre el 2008 y 2010.

Material y Método: El enfoque de la investigación fue mixto, de nivel descriptivo explicativo, de corte transversal - retrospectivo. El área geográfica del estudio

1. Facultad de Filosofía, Universidad Nacional de Asunción, Paraguay.

Investigación fue presentada para optar por el título de Magíster en Ciencias de la Educación con énfasis en Administración Educacional en la Facultad de Filosofía. Universidad Nacional de Asunción. La investigación fue iniciada en abril de 2011.

E-mail: elviravirginiasam@gmail.com

DOI: $10.26885 /$ rcei.foro. 2017.73 
se centró en las zonas escolares del Departamento Central. La población estuvo conformada por 13 supervisores. La muestra fue no probabilística intencional. El área geográfica del estudio se centró en las zonas escolares de Supervisión F, $\mathrm{S}$, E y C del nivel de Educación Escolar Básica (EEB) del Departamento Central. Se seleccionaron cuatro supervisores que, a criterio de los Coordinadores Departamentales de Supervisión, fueron calificados con "muy buen desempeño en sus funciones". Se realizó el estudio en 16 escuelas. Se entrevistó a 16 directores, 48 docentes y 48 alumnos.

Los métodos y las técnicas utilizados fueron: observación de campo, encuesta y entrevista semiestructurada. Los instrumentos: registro de observación, cuestionario y guía de entrevista. El procesamiento de resultados se realizó con ayuda de gráficos en formato Excel, cuadros en formato Word. Los datos consignados fueron utilizados exclusivamente para la elaboración de esta Tesis y se ha garantizado la confidencialidad.

Resultados: El estudio de los cuatro casos ha arrojado resultados muy similares de acuerdo a los parámetros definidos previamente. Los supervisores considerados de buena gestión por sus jefes directos, demostraron un perfil similar de gestión como guía y facilitador, encaminado hacia el mejoramiento y desarrollo de las instituciones a su cargo. Los supervisores se perciben a sí mismos con buen liderazgo para orientar su gestión, son responsables y de estilo democrático. Los supervisores utilizan estrategias y realizan varias actividades para apoyar la gestión pedagógica de los directores y docentes, a fin de lograr la calidad educativa en las instituciones que supervisan.

Cada supervisor cuenta con un equipo técnico conformado por profesionales idóneos, que coadyuvan con ellos en su gestión.

Los supervisores trabajan con las instituciones a su cargo a través de proyectos pedagógicos, círculos de aprendizajes, seminarios, otras actividades para lograr el mejoramiento educativo institucional. Desde el estamento de directores todos han opinado que la labor de sus supervisores era muy importante para el mejoramiento institucional. Los supervisores pedagógicos de las cuatro zonas realizan muy buena gestión en las escuelas a su cargo, según los resultados de entrevistas a directores y docentes.

Los supervisores utilizan diversas estrategias y realizan varias actividades para apoyar la gestión pedagógica de los directores y docentes, a fin de lograr la calidad educativa a través de proyectos pedagógicos, círculos de aprendizajes, seminarios, etc.

Los directores y docentes encuentran apoyo y acompañamiento de los supervisores, en sus gestiones. Los supervisores tienen un tipo democrático de liderazgo reconocido por todos los entrevistados (directores y docentes) y estilo de gestión de facilitador y guía tendiente a ser transformador y de desarrollo de las instituciones.

Conclusiones: Se concluyó que en el 100\% de los casos estudiados, ha sido demostrado un alto grado de incidencia de los supervisores en el mejoramiento 
de las instituciones educativas de las zonas a su cargo, en el periodo de un trabajo procesual y permanente de tres años o más, ya sea con un fuerte apoyo y motivación a los directores, como por intervenciones oportunas del supervisor en resolución de conflictos, capacitaciones y visitas de los supervisores, a la institución.

En vistas a las dimensiones que han sido orientadas para atender, los supervisores pedagógicos del MEC deberían: minimizar las dificultades que tienen en su gestión a través de sus propias fortalezas, para conseguir cambios y mejoras en educación y transformar las instituciones.

El supervisor debe ser consciente de su misión: Guiar a los supervisados hacia la meta de encontrar cómo hacer de las escuelas, espacios de formación de la dignidad y la conciencia ciudadana de niños y jóvenes, con respeto y alegría para vivir la vida con calidad y transcendencia.

Palabras clave: gestión, supervisión, mejora escolar, liderazgo.

\section{Referencias}

Educar Chile. (2004). El portal de la Educación. Experiencias internacionales en supervisiones escolar. Sistematización y análisis comparado. Santiago: Dirección de Estudios Sociológicos de la Universidad Católica de Chile.

Gvirtz, S., Podestá M. (2009). El rol del supervisor en la mejora escolar. Buenos Aires: Aique Grupo Editor.

Ministerio de Educación y Cultura. (2009). Plan de Educación 2024: hacia el centenario de la escuela nueva de Ramón Indalecio Cardozo. Asunción: MEC.

Rivera Ferreiro, L. (2007). ¿ Qué supervisores necesita la escuela básica para apoyar su transformación? Revista de educación y cultura La Tarea. Recuperado de http://www.latarea.com.mx/articu/articu18/rivera.htm

Uruñuela, P. (2009).Supervisión Educativa Módulo IIIA. Funciones de control evaluación y asesoramiento en la supervisión externa. Curso Experto Universitario en Administración de la Educación Supervisión Educativa. CADE. 